\title{
Crystal Structure of Glucagon-like Peptide-1 in Complex with the Extracellular Domain of the Glucagon-like Peptide-1 Receptor
}

Underwood, Christina Rye; Garibay, P.; Knudsen, L.B.; Hastrup, S.; Peters, Günther H.J.; Rudolph, R.; Reedtz-Runge, S.

Published in:

Journal of Biological Chemistry

Link to article, DOI:

10.1074/jbc.M109.033829

Publication date:

2010

Document Version

Publisher's PDF, also known as Version of record

Link back to DTU Orbit

Citation $(A P A)$ :

Underwood, C. R., Garibay, P., Knudsen, L. B., Hastrup, S., Peters, G. H. J., Rudolph, R., \& Reedtz-Runge, S. (2010). Crystal Structure of Glucagon-like Peptide-1 in Complex with the Extracellular Domain of the Glucagonlike Peptide-1 Receptor. Journal of Biological Chemistry, 285(1), 723-730.

https://doi.org/10.1074/jbc.M109.033829

\section{General rights}

Copyright and moral rights for the publications made accessible in the public portal are retained by the authors and/or other copyright owners and it is a condition of accessing publications that users recognise and abide by the legal requirements associated with these rights.

- Users may download and print one copy of any publication from the public portal for the purpose of private study or research.

- You may not further distribute the material or use it for any profit-making activity or commercial gain

- You may freely distribute the URL identifying the publication in the public portal 


\section{Crystal Structure of Glucagon-like Peptide-1 in Complex with the Extracellular Domain of the Glucagon-like Peptide-1 Receptor ${ }^{*[5}$}

Received for publication, June 17, 2009, and in revised form, September 21, 2009 Published, JBC Papers in Press, October 27, 2009, DOI 10.1074/jbc.M109.033829

Christina Rye Underwood $^{\ddagger \S}$, Patrick Garibay", Lotte Bjerre Knudsen", Sven Hastrup ${ }^{* *}$, Günther H. Peters ${ }^{\S 1}$, Rainer Rudolph ${ }^{\neq \neq}$, and Steffen Reedtz-Runge ${ }^{\S \S 2}$

From the Departments of ${ }^{\ddagger}$ GLP-1 and Obesity Biology, "Protein and Peptide Chemistry, "Diabetes Biology and Pharmacology, **Protein Expression, and ${ }^{\S \S}$ Structure and Biophysical Chemistry, Novo Nordisk, 2760 Måløv, Denmark, the ${ }^{\S}$ Department of Chemistry, MEMPHYS Center for Biomembrane Physics, Technical University of Denmark, 2800 Kgs. Lyngby, Denmark, and the

${ }^{\ddagger \neq}$ Institute for Biochemistry and Biotechnology, Martin Luther University Halle, Wittenberg, 06120 Halle, Germany

GLP-1 (glucagon-like peptide-1) is an incretin released from intestinal L-cells in response to food intake. Activation of the GLP-1 receptor potentiates the synthesis and release of insulin from pancreatic $\beta$-cells in a glucose-dependent manner. The GLP-1 receptor belongs to class B of the G-protein-coupled receptors, a subfamily characterized by a large $\mathrm{N}$-terminal extracellular ligand binding domain. Exendin-4 and GLP-1 are 50\% identical, and exendin- 4 is a full agonist with similar affinity and potency for the GLP-1 receptor. We recently solved the crystal structure of the GLP-1 receptor extracellular domain in complex with the competitive antagonist exendin-4(9-39). Interestingly, the isolated extracellular domain binds exendin-4 with much higher affinity than the endogenous agonist GLP-1. Here, we have solved the crystal structure of the extracellular domain in complex with GLP-1 to $2.1 \AA$ resolution. The structure shows that important hydrophobic ligand-receptor interactions are conserved in agonist- and antagonist-bound forms of the extracellular domain, but certain residues in the ligand-binding site adopt a GLP-1-specific conformation. GLP-1 is a kinked but continuous $\alpha$-helix from $\mathrm{Thr}^{13}$ to $\mathrm{Val}^{33}$ when bound to the extracellular domain. We supplemented the crystal structure with site-directed mutagenesis to link the structural information of the isolated extracellular domain with the binding properties of the full-length receptor. The data support the existence of differences in the binding modes of GLP-1 and exendin-4 on the full-length GLP-1 receptor.

GLP-1 (glucagon-like peptide-1) is a peptide hormone produced by post-translational processing of proglucagon in the

* This work was supported in part by a scholarship from Novo Nordisk A/S (to C.R. U.), European Membrane Protein Consortium, the Federal State of Saxony-Anhalt Grant 3324 A/0021 L, and the Deutsche Forschungsgemeinshaft Grant SFRB 610/TP A11.

$\therefore$ Author's Choice-Final version full access.

5 The on-line version of this article (available at http://www.jbc.org) contains supplemental Fig. S1.

The atomic coordinates and structure factors (code 3/OL) have been deposited in the Protein Data Bank, Research Collaboratory for Structural Bioinformatics, Rutgers University, New Brunswick, NJ (http://www.rcsb.org/).

${ }^{1}$ Supported by the Danish National Research Foundation via a grant to the MEMPHYS Center of Biomembrane Physics.

${ }^{2}$ To whom correspondence should be addressed: Novo Nordisk Park, G8.S.439, DK-2760 Måløv, Denmark. Tel.: 45-44434431; E-mail: sffr@ novonordisk.com. intestinal L-cells (1). GLP-1 is an incretin that potentiates the synthesis and release of insulin from pancreatic $\beta$-cells in a glucose-dependent manner (2) and has a number of other beneficial effects that contribute to reducing blood sugar (3-6). In addition, GLP-1 has been shown to reduce body weight $(3,5,7)$, which is favorable for many people with type 2 diabetes. Hence, GLP-1-based therapies are becoming increasingly attractive for the treatment of type 2 diabetes. The actions of GLP-1 are mediated through the GLP-1 receptor (GLP-1R), ${ }^{3}$ which is a seven-transmembrane $G$ protein-coupled receptor (GPCR) coupled to adenylyl cyclase (8). The human GLP-1R was first cloned in 1992 and belongs to class B of GPCRs (9). This class includes a wide range of receptors for peptide hormones like glucagon, GLP-2 (glucagon-like peptide-2), glucosedependent insulinotropic polypeptide (GIP), pituitary adenylyl cyclase-activating polypeptide (PACAP), vasoactive intestinal polypeptide, secretin, calcitonin, corticotrophinreleasing factor, and parathyroid hormone (PTH) (10). The receptors are distinguished by their large extracellular $\mathrm{N}$-terminal domain (ECD), which is important for ligand binding and selectivity $(11,12)$. The current binding model suggests a two-domain mechanism where the C-terminal part of the ligand binds the ECD and the N-terminal part of the ligand binds the extracellular loops and transmembrane $\alpha$-helices (TM domain), which leads to receptor activation (reviewed in Ref. 13).

The first structure of an isolated ECD of a class B GPCR was solved recently by NMR spectroscopy (14). Subsequently, structures of ligand-bound ECDs were solved, including the ECD of the human type 1 corticotrophin-releasing factor receptor 1 (15), the human type 1 PACAP receptor (16), the human GIP receptor (17), the human GLP-1R (18), and the human type 1 PTH receptor (19). The ECDs of class B receptors have a common structure, the secretin recognition fold, which is stabilized by three conserved disulfide bonds and five conserved residues $\left(\mathrm{Asp}^{67}, \operatorname{Trp}^{72}, \operatorname{Pro}^{86}, \mathrm{Gly}^{108}\right.$, and $\operatorname{Trp}^{110}$ in GLP$1 \mathrm{R})$. The receptor-bound ligands are primarily in $\alpha$-helical con-

\footnotetext{
${ }^{3}$ The abbreviations used are: GLP-1R, GLP-1 receptor; GPCR, G protein-coupled receptor; GIP, glucose-dependent insulinotropic polypeptide; PACAP, pituitary adenylyl cyclase-activating polypeptide; PTH, parathyroid hormone; ECD, extracellular N-terminal domain; TM domain, extracellular loops and transmembrane $\alpha$-helices.
} 
formation, and the C-terminal part of the ligands binds the ECD in agreement with the two-domain binding mechanism. Several receptor models have been proposed for full-length class $B$ receptors $(20-23)$. However, the orientation of the ECD relative to the TM domain is uncertain.

Exendin-4 is a 39-amino acid peptide, which was originally isolated from the venom of the lizard Heloderma suspectum (24). GLP-1 and exendin-4 are 50\% identical, and exendin-4 is a full agonist with similar affinity and potency for the full-length GLP-1R (25). However, structure-activity studies have demonstrated interesting differences between the binding modes of GLP-1 and exendin-4. 1) The isolated ECD binds exendin-4 with high affinity $\left(\mathrm{IC}_{50}\right.$ of $\left.6 \mathrm{nM}\right)$ and GLP-1 with low affinity $\left.\left(\mathrm{IC}_{50}>500 \mathrm{nM}\right)(26,27) .2\right)$ GLP-1 binding is more sensitive to site-directed mutagenesis of the TM domain compared with exendin-4 binding (28-30). 3) GLP-1 is much more sensitive to $\mathrm{N}$-terminal truncation than exendin-4 (31). N-terminally truncated exendin-4 variants maintain high affinity but are unable to activate GLP-1R, i.e. competitive antagonist, whereas N-terminal truncation of GLP-1 severely affects both binding and activation (31). Clearly, the interaction between the $\mathrm{N}$-terminal part of GLP-1 and the TM domain is critical for binding and activation of GLP-1R.

Exendin-4(9-39) is a truncated form of exendin-4, and a competitive antagonist that maintains high affinity for GLP-1R through interactions with the ECD ( $\mathrm{IC}_{50}$ value of $6 \mathrm{nM}$ for the isolated ECD) $(27,32)$. We recently solved the crystal structure of the GLP-1R ECD in complex with exendin-4(9-39) (18). Exendin-4(9-39) is $\alpha$-helical in the ECD-bound conformation except for the C-terminal segment, the so-called Trp cage (33, 34). In solution, the helical propensity of exendin-4 is higher than that of GLP-1 $(27,33)$. Biophysical studies showed a positive correlation between $\alpha$-helical propensity in solution and affinity for the GLP-1R ECD (27). Moreover, charged residues of exendin-4 interact with the ECD in a manner not possible for GLP-1 (18). Hence, the high affinity of exendin-4 for the ECD may be a combination of high helical propensity in solution and unique receptor interactions.

Here, we report the crystal structure of the GLP-1R ECD in complex with its endogenous agonist GLP-1. We supplemented the crystal structure with site-directed mutagenesis to link the structural information of the isolated ECD with the binding properties of the full-length receptor.

\section{EXPERIMENTAL PROCEDURES}

Protein and Peptide Preparation-The GLP-1R ECD was prepared as described previously (27). Briefly, N-terminal $\mathrm{His}_{6}-$ tagged ECD was expressed in Escherichia coli inclusion bodies, isolated as inclusion body protein, solubilized in guanidine- $\mathrm{HCl}$ and dithiothreitol, dialyzed against guanidine- $\mathrm{HCl}$ to remove the dithiothreitol, and refolded using L-Arg and a 1:5 molar ratio of reduced and oxidized glutathione. The refolded ECD was purified by hydrophobic interaction chromatography and size exclusion chromatography in $10 \mathrm{~mm}$ Tris- $\mathrm{HCl}, \mathrm{pH}$ 7.5, 0.1 $\mathrm{M} \mathrm{Na}_{2} \mathrm{SO}_{4}, 2 \%$ glycerol. The His ${ }_{6}$ tag was removed by thrombin cleavage. The purified GLP-1R ECD consisted of four amino acids, Gly-Ser-His-Met, of the linker attached to the N-terminus of ECD $\left(\mathrm{Arg}^{24}-\mathrm{Tyr}^{145}\right), M_{\mathrm{r}}=14,723 \mathrm{~g} / \mathrm{mol}$ after removal of the $\mathrm{His}_{6}$ tag. Native GLP-1(7-37)-OH was synthesized as described previously (12).

Purification and Crystallization of the GLP-1-bound Extracellular Domain - The purified GLP-1R ECD was concentrated to $1.2 \mathrm{mg} / \mathrm{ml}$, mixed with 3-fold molar excess of GLP-1(7-37) (dissolved in $50 \mathrm{~mm}$ Tris- $\mathrm{HCl}, \mathrm{pH} 7.5$ ), and incubated overnight at $4{ }^{\circ} \mathrm{C}$. The GLP-1-bound ECD was purified by size exclusion chromatography on a Superdex 75 column in $10 \mathrm{~mm}$ Tris- $\mathrm{HCl}$, $\mathrm{pH} 7.5$, at a flow rate of $0.3 \mathrm{ml} / \mathrm{min}$ and characterized by SDSPAGE (supplemental Fig. S1). The complex was concentrated to $4 \mathrm{mg} / \mathrm{ml}$ and crystallized by hanging drop vapor diffusion. The crystallization conditions were initially identified using the Crystal Screen from Hampton Research and subsequently optimized to $0.1 \mathrm{M} N(2$-acetamido)iminodiacetic acid, $\mathrm{pH} 6.9,14$ volume \% (士)-2-methyl-2,4-pentanediol and $9 \mathrm{~mm} n$-decyl- $\beta$ D-thiomaltoside. Single crystals were flashed cooled in liquid $\mathrm{N}_{2}$ using 30\% glycerol in the cryo solution.

Data Collection and Structure Determination-Diffraction data were collected from a single crystal using beamline 1911-3 at MAX-lab (Lund, Sweden). The data were integrated and scaled using XDS (35). The crystals belonged to space group P2 $22_{1}$ with the unit cell dimensions $a=35.7 \AA, b=42.7 \AA$, and $c=95.1 \AA$. The phases and electron density map were obtained by molecular replacement using Phaser running in the CCP4 program interface with one complex in the asymmetric unit. Refinement was done using COOT (36) and REFMAC5 (37). Well defined electron density was obtained for GLP-1 residues $\mathrm{Thr}^{11 *}-\mathrm{Val}^{33 *}$ and for ECD residues $\mathrm{Val}^{30}-\mathrm{Glu}^{128}$. Poor density was observed for GLP-1 residues $\mathrm{Gly}^{10 *}$,ys $^{34 *}$, and Gly ${ }^{35 *}$ and ECD residues $\mathrm{Thr}^{29}$ and $\mathrm{Asn}^{115}$. No electron density was observed for $\mathrm{His}^{7 *}-\mathrm{Glu}^{9 *}$ and $\mathrm{Arg}^{36 *}-\mathrm{Gly}^{37 *}$ of GLP-1. Our final structure contains GLP-1 residues Gly ${ }^{10 *}-$ Gly $^{35 *}$ and ECD residues $\mathrm{Thr}^{29}-\mathrm{Glu}^{128}$, but it should be noted that the conformation of Lys ${ }^{34 *}$ of GLP-1 is very uncertain, and because of the poor density we have chosen to show Asn $^{115}$ as Gly. The final GLP-1-bound ECD structure has 116 residues in preferred regions, 5 in allowed regions and only 1 outlier $\left(\mathrm{Glu}^{68}\right.$ in the $\beta$-turn between $\beta_{1}$ and $\beta_{2}$ shown in Fig. $1 A$ ) in the Ramachandran plot. The structure containing 73 water molecules and a detergent molecule ( $n$-decyl- $\beta$-D-thiomaltoside) has a working $R$-factor of $0.181 \%$ and a free $R$-factor of $0.226 \%$. Data collection and refinement statistics are summarized in Table 1. Coordinates and structure factors are deposited in the Protein Data Bank under accession code 3IOL. Molecular graphics were prepared in PyMOL (46).

Receptor Constructs - The cDNA encoding the human GLP$1 \mathrm{R}$ was originally obtained from Dr. B. Thorens (9) and subcloned into the mammalian expression vector pcDNA3.1/ v5-His-TOPO ${ }^{\circledR}$ (Invitrogen). The presence of the C-terminal $\mathrm{His}_{6}$ tag was previously shown not to influence the functional response of the receptor (12). Site-directed mutagenesis of GLP-1R was done using QuikChange ${ }^{\mathrm{TM}}$ (Stratagene). Plasmid DNA was generated using the NucleoBond ${ }^{\circledR}$ Xtra Maxi Plus kit (Macherey-Nagel), and the desired mutations were confirmed by dideoxynucleotide sequencing.

Cell Culture and Receptor Expression-Human embryonic kidney (HEK) 293 cells were maintained in Dulbecco's modified Eagle's medium (BioWhittaker) supplemented with 10 volume 

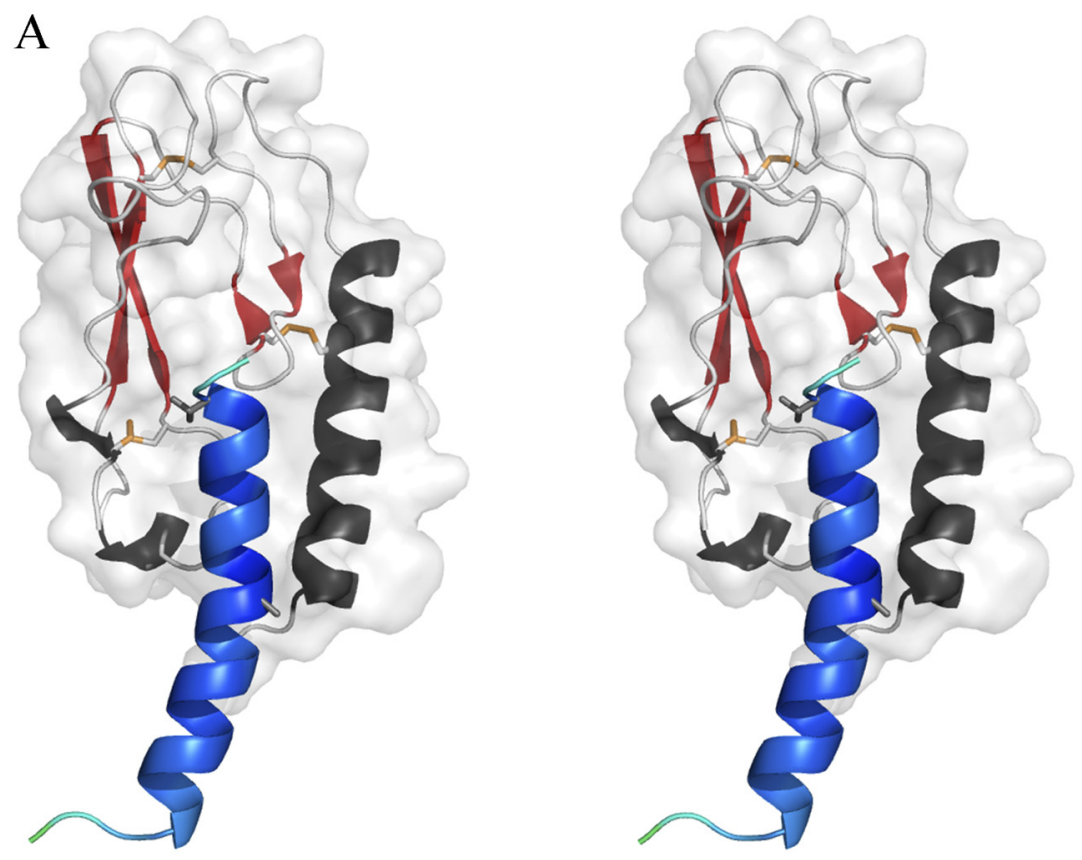

B GLP-1 (7-37) HAEGTFT SDVSSYLEGQAAKEFIANLVKGRG

Exendin-4 HGEGT FT SDLSKQME EEAVRLFIEWLLKNGGPS SGA.PPPS

GI P GLP-2 YAEGT FI SDY SI AMDKI HQQDF VNW LLAQKGKKNDWKHNITQ Glucagon PACAP $(1-27)$

\section{HADGS F S DEMNT ILDNLA.ARDF INW LIQTKIT D \\ HSQGTFT SDY SKYLDSRRAQDFVQW LMNT \\ HSDGIFTDSYSRYRKQMAVKKYLAAVL}

\section{$\begin{array}{llllllll}1 & 5 & 10 & 15 & 20 & 25 & 30 & 35\end{array}$}

FIGURE 1. Structure of the GLP-1-bound ECD of the GLP-1R. $A$, stereoview of GLP-1 (blue) bound to the ECD of the GLP-1R ( $\alpha$-helix in black, $\beta$-strands in red, and loops in gray). Disulfide bridges are shown as orange sticks. Residues $\mathrm{Cys}^{62}-\mathrm{Asp}^{67}\left(\beta_{1}\right)$ and $\mathrm{Ala}^{70}-\mathrm{Gly}^{75}\left(\beta_{2}\right)$ constitute the first region of antiparallel $\beta$-sheets, and the second region is comprised of residues $\mathrm{Gly}^{78}-\operatorname{Ser}^{84}\left(\beta_{3}\right)$ and $\mathrm{His}^{99}-\operatorname{Thr}^{105}\left(\beta_{4}\right)$, which is shown in red. Our final structure contains GLP-1 residues Gly ${ }^{10 *}-G_{1} y^{35 *}$. The residues that interact with GLP-1R ECD lie within Ala ${ }^{24 *}$ and $\mathrm{Val}^{33 *}$, which are shown as sticks. B, sequence alignment of GLP-1, exendin-4, GIP, GLP-2, glucagon, and PACAP(1-27). Fully conserved residues are highlighted in yellow, and partially conserved residues are highlighted in green. The residues of GLP-1 and exendin-4 that interact with GLP-1R ECD are colored blue. The underlined residues symbolize residues of GLP-1 in $\alpha$-helical conformation when bound to the ECD. Residue number 1 of exendin- 4 corresponds to residue number 7 of GLP-1.

$\%$ fetal bovine serum and 1 volume \% penicillin/streptomycin (100 units/ml) in T175 flasks. HEK293 cells were transiently transfected with $21 \mu \mathrm{g}$ of GLP-1R DNA using the FuGENE ${ }^{\mathrm{TM}}$ transfection reagent (Roche Applied Science), harvested $24 \mathrm{~h}$ after transfection, and used directly in functional experiments or plasma membrane preparations as described previously (12).

Functional Assay-Transiently transfected HEK293 cells expressing wild-type GLP-1R or mutant receptors were harvested and resuspended in assay buffer (Flashplate ${ }^{\circledR}$, PerkinElmer Life Sciences) to a cell density of $2.4 \times 10^{6}$ cells/ ml. GLP-1(7-37)-acid and exendin-4 were diluted in phosphate-buffered saline with 0.02 volume $\%$ Tween 20. Cells in assay buffer (50 $\mu \mathrm{l})$ and GLP-1 or exendin-4 (50 $\mu \mathrm{l})$ were mixed in 96-well FlashPlates ${ }^{\circledR}$ (PerkinElmer Life Sciences), gently agitated for $5 \mathrm{~min}$, and incubated for $25 \mathrm{~min}$ at room temperature. The resulting intracellular level of cAMP was measured according to supplier's manual and analyzed by nonlinear regression/ sigmoidal dose-response fitting using Prism 5.0 ${ }^{\circledR}$ (GraphPad Software, Inc.).
Receptor Binding Assay-Freshly thawed plasma membrane preparations from transiently transfected HEK293 cells expressing GLP-1R (20 $\mu \mathrm{g}$ protein/well) were pulled through a 25 -gauge needle three times and diluted in assay buffer ( 50 mM HEPES, $5 \mathrm{~mm} \mathrm{MgCl}_{2}, 5 \mathrm{~mm}$ EGTA, 0.005 volume \% Tween 20, pH 7.4). GLP-1 and exendin-4 were diluted in assay buffer. The concentration range was $1 \mathrm{pM}$ to $100 \mathrm{nM}$ for GLP-1 and exendin-4. ${ }^{125}$ I-GLP1(7-36)-amide $(2.2 \mathrm{Ci} / \mu \mathrm{mol})$ was dissolved in assay buffer and added at $50,000 \mathrm{cpm}$ per well to a final concentration of 50 pм. Nonspecific binding was determined with $1 \mu \mathrm{M}$ GLP-1. Membrane preparation and radioligand were mixed in 96-well $0.65-\mu \mathrm{m}$ filter plates (Millipore) with either diluted GLP-1 or exendin- 4 and incubated for $1 \mathrm{~h}$ at $37^{\circ} \mathrm{C}$. Subsequently, bound and unbound radioligands were separated by vacuum filtration (Millipore vacuum manifold). The filters were washed twice in $100 \mu \mathrm{l}$ of cold assay buffer and left to dry. Data were analyzed by nonlinear regression, and the expression level $\left(B_{\max }\right)$ was calculated using Prism 5.0 ${ }^{\circledR}$ (GraphPad Software, Inc.).

\section{RESULTS AND DISCUSSION}

Purification, Crystallization, and Structure Determination-The GLP1R ECD was expressed in E. coli inclusion bodies, refolded, and purified as described previously (27). A complex of GLP-1 and the ECD was purified by size exclusion chromatography (supplemental Fig. S1). The purified complex was characterized by SDS-PAGE (supplemental Fig. S1), concentrated, and crystallized by hanging drop vapor diffusion. Diffraction data were collected from a single crystal using the beamline 1911-3 at MAX-lab (Lund, Sweden), and the structure of GLP-1 in complex with the GLP-1R ECD was solved to $2.1 \AA$ resolution by molecular replacement (Fig. $1 A)$. We removed exendin-4(9-39) from the structure of the exendin-4(9-39)-ECD complex (Protein Data Bank code 3C59) and used the apo-form of GLP-1R ECD as the search model for the molecular replacement. GLP-1 was then built into the model; its position was unambiguous due to good electron density for most of the ligand. Data collection and refinement statistics are summarized in Table 1. Throughout the text, GLP-1 and exendin-4 residues are designated with * and **, respectively. Exendin-4 is numbered 1-39 and GLP-1 is numbered 7-37, due to post-translational processing. The aligned sequences are illustrated in Fig. $1 B$. 
Structure of the GLP-1R Extracellular Domain-The crystal structure of the ECD in the GLP-1-bound form shown here is very similar to the exendin-4(9-39)-bound form shown previously (root mean square deviation of $0.79 \AA$ for $C^{\alpha}$ atoms of the ECD) (18). The ligand-binding sites are identical, which is not surprising given the competitive binding of GLP-1 and exendin-4 for the full-length GLP-1R as well as the isolated ECD (27). However, we have previously shown that divergent residues in the two ligands are responsible for their different physical properties in solution and their different affinity for the ECD (27). As described below, these divergent residues give rise to structural differences in the two ligand-bound forms of the ECD at the level of specific side chain conformations.

\section{TABLE 1}

\section{Data collection and refinement statistics}

The data set was collected from a single crystal. Values in parentheses are for the highest resolution shell (2.2-2.1 $)$.

\begin{tabular}{lc}
\hline Space group & $\mathrm{P} 2_{1} 22_{1}$ \\
\hline Unit cell dimensions $(\AA)$ & 35.7 \\
$A$ & 42.7 \\
$B$ & 95.1 \\
\hline Data collection & $1.0 \AA$ \\
Wavelength & $-2.1 \AA(2.2-2.1 \AA)$ \\
Resolution range & 73,811 \\
Total reflections & 10,348 \\
Unique reflections & $97.9 \%$ \\
Completeness & $14.0(5.3)$ \\
$I / \sigma(I)$ & $11.1(44.9)$ \\
$R_{\text {sym }}$ & \\
Refinement statistics & 1109 \\
No. of non-hydrogen atoms & 8786 \\
Resolution & 429 \\
Total reflections & $0.181(0.187)$ \\
Reflections in test set & $0.226(0.255)$ \\
$R_{\text {work }}$ & 13.6 \\
$R_{\text {free }}$ & \\
Average $B$-factors & $0.02 \AA$ \\
Root mean square deviation & $1.7^{\circ}$ \\
Bond lengths & \\
Bond angles & $95.1-2.1 \AA)$ \\
\hline
\end{tabular}
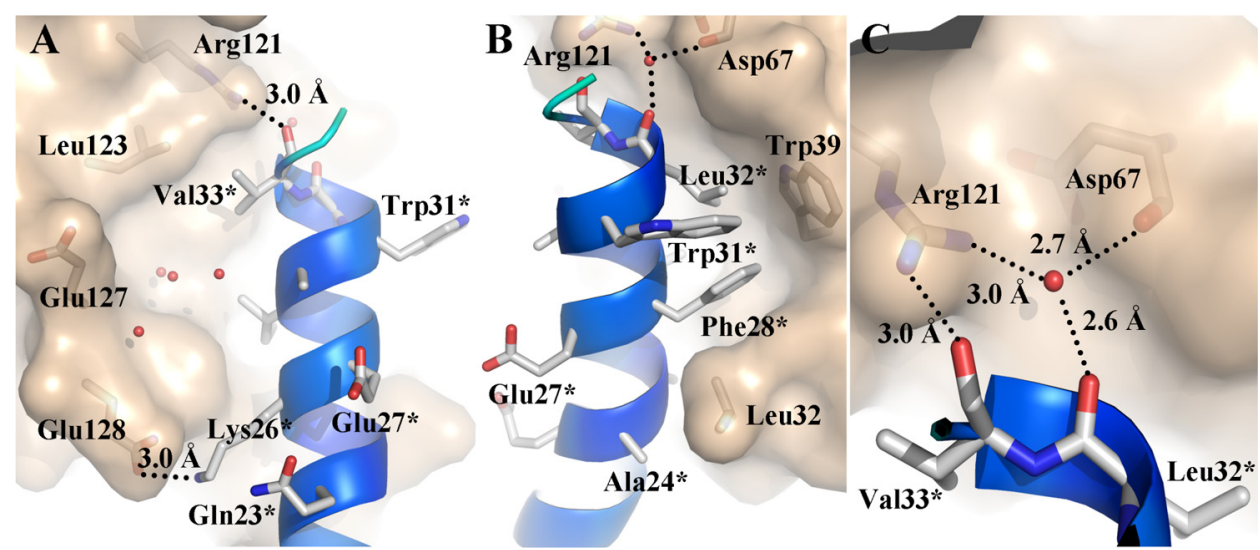

FIGURE 2. Interactions between GLP-1 and GLP-1R ECD. A, ribbon diagram of GLP-1 and its hydrophilic interactions with GLP-1RECD. GLP-1 is colored in cyan, and residues Gln ${ }^{23 *}$, Lys ${ }^{26 *}, \mathrm{Glu}^{27 *}, \operatorname{Trp}^{31 *}$, and Val ${ }^{33 *}$ are illustrated as sticks. Receptor residues $\mathrm{Arg}^{121}, \mathrm{Leu}^{123}, \mathrm{Glu}^{127}$, and $\mathrm{Glu}^{128}$ are shown as sticks. The surface of the hydrophilic binding cavity of ECD is illustrated in gray. B, ribbon diagram of GLP-1 and its hydrophobic interactions with GLP-1R ECD. GLP-1 residues $\mathrm{Ala}^{24 *}, \mathrm{Glu}^{27 *}, \mathrm{Phe}^{28 *}$, $\operatorname{Trp}^{31 *}$, and $\mathrm{Leu}^{32 *}$ are illustrated as sticks, and so are ECD residues Leu ${ }^{32}, \operatorname{Trp}^{39}, \mathrm{Asp}^{67}$, and $\mathrm{Arg}^{121}$. The surface of the hydrophobic binding cavity of ECD is illustrated in gray. $C$, ribbon diagram illustrating a common motif found in the GLP-1R ECD and in the GIP receptor ECD. The side chain of $\mathrm{Arg}^{121}$ interacts with the backbone carbonyls of $\mathrm{Asp}^{67}$ and $\mathrm{Leu}^{32 *}$ through a water molecule. GLP-1 residues Leu ${ }^{32 *}$ and Val ${ }^{33 *}$ are illustrated as sticks, and so are ECD residues Asp ${ }^{67}$ and $\operatorname{Arg}^{121}$
Structure of GLP-1 and Its Interactions with the Extracellular Domain of GLP-1R-GLP-1 is a continuous $\alpha$-helix from $\mathrm{Thr}^{13 *}$ to $\mathrm{Val}^{33 *}$, with a kink around $\mathrm{Gly}^{22 *}$. The residues between $\mathrm{Ala}^{24 *}$ and $\mathrm{Val}^{33 *}$ interact with the ECD (Fig. 1, $A$ and $B)$. The amphiphilic nature of this $\alpha$-helical segment enables hydrophilic and hydrophobic interactions through opposite faces of the $\alpha$-helix. The hydrophilic face is comprised by residues $\operatorname{Gln}^{23 *}$, Lys $^{26 *}$, Glu $^{27 *}$, and Lys $^{34 *}$. Lys $^{26 *}$ is the only one of these that may interact directly with the ECD (Fig. $2 A$ ). The side chain of Lys ${ }^{26 *}$ may form a hydrogen bond with the side chain of Glu $^{128}(\sim 3.0 \AA)$, but the $B$-factor is rather high for both residues $\sim 25$ compared with 10 for well defined residues), suggesting that this is not a strong interaction. In particular, the electron density of the Lys ${ }^{26 *}$ side chain is rather weak. In exendin-4(9$39)$, the amphiphilic character is more pronounced, and the $\alpha$-helical conformation is further stabilized by intramolecular interactions between $\mathrm{Glu}^{16 \%}, \mathrm{Glu}^{17 * *} \mathrm{Arg}^{2 \mathrm{O} * *}, \mathrm{Glu}^{24 \% *}$, and Lys $^{27 * *}$ on the hydrophilic face (18). In addition, $\operatorname{Arg}^{20 * *}$ and Lys $^{27 * *}$ interact with Glu ${ }^{128}$ and Glu ${ }^{127}$ of the ECD, respectively (18). The corresponding intramolecular stabilization is not possible in GLP-1 due to a less favorable alignment of oppositely charged residues (Fig. $1 B$ ), and $\mathrm{Glu}^{127}$ of the ECD is not involved in binding of GLP-1 (Fig. 2A).

The hydrophobic face of GLP-1, which interacts with the ECD, is defined by $\mathrm{Ala}^{24 *}, \mathrm{Ala}^{25 *}, \mathrm{Phe}^{28 *}, \mathrm{Ile}^{29 *}, \mathrm{Leu}^{32 *}$, and $\mathrm{Val}^{33 *}$ (Fig. 2B). The importance of Phe $\mathrm{Ph}^{28 *}, \mathrm{Ile}^{29 *}$, and $\mathrm{Leu}^{32 *}$ in GLP-1 binding has been demonstrated previously by Ala scanning of GLP-1 (38). Substitution of Phe ${ }^{28 *}$ with Ala had the most severe effect on GLP-1 affinity in the Ala scan $\left(\mathrm{IC}_{50}\right.$ value increased by 1300 -fold), and indeed Phe ${ }^{28 *}$ is centrally positioned in the ligand-receptor interface emphasizing the importance of this hydrophobic ligand-receptor interaction. The I29*A and L32*A substitutions also reduced GLP-1 affinity significantly ( $\mathrm{IC}_{50}$ value increased by 93 - and 17 -fold, respectively) (38). $\operatorname{Trp}^{31 *}$ is also on the hydrophobic face of GLP-1 but is rather solvent-exposed and does not interact with the ECD

(Fig. 2B). $\operatorname{Trp}^{31 *}$ is conserved in the glucagon peptide family (GLP-1, exendin-4, glucagon, GIP, and GLP-2, see Fig. $1 B$ ), which implies a unique role of this residue. However, substitution of $\operatorname{Trp}^{31 *}$ with Ala only reduced the binding affinity of GLP-1 slightly at the full-length GLP-1R (38), so the role of $\operatorname{Trp}^{31 *}$ in receptor binding is unclear.

$\mathrm{Val}^{33 *}$ is the final residue in the $\alpha$-helix of GLP-1, and it is the final residue in the $C$ terminus of GLP-1 that interacts with the ECD (Fig. 2, $A$ and $C$ ). The side chain of $\mathrm{Val}^{33 *}$ makes hydrophobic contacts with $\mathrm{Tyr}^{69}$ and Leu ${ }^{123}$, and the backbone carbonyl of $\mathrm{Val}^{33 *}$ interacts through a hydrogen bond with one of the terminal nitrogens of $\mathrm{Arg}^{121}$ (Fig. 2, A and $C$ ). The other terminal nitrogen of $\mathrm{Arg}^{121}$ interacts with a water mol- 

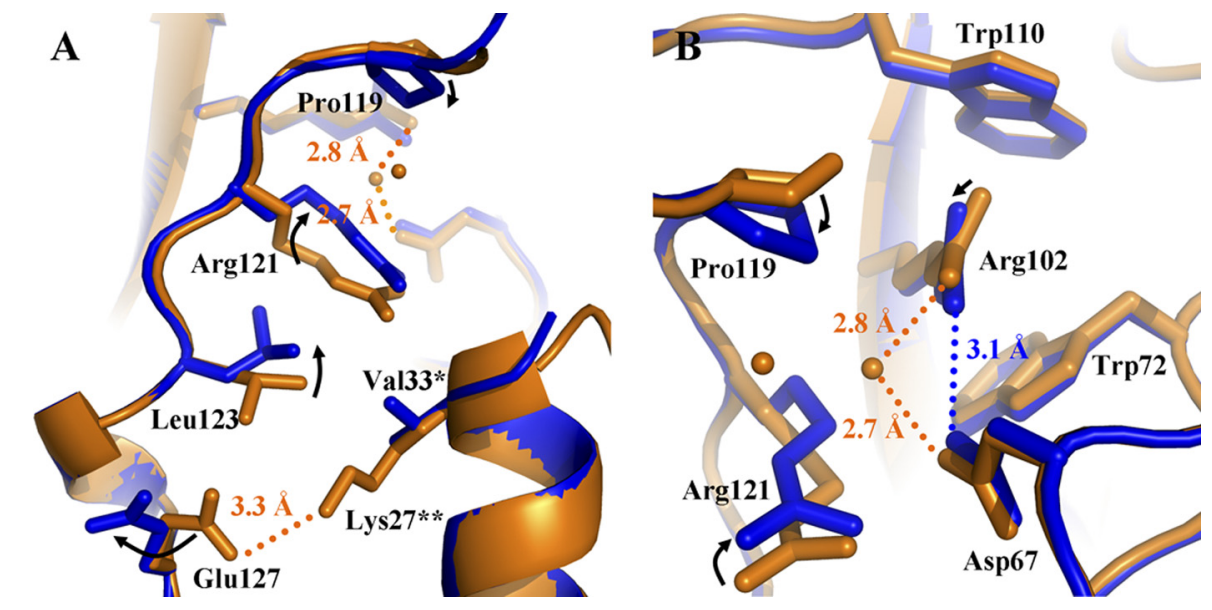

FIGURE 3. Differences between the GLP-1- and exendin-4(9-39)-bound structure of ECD. Ribbon diagrams showing significant differences in side chain conformations between the GLP-1-bound structure and the exendin-4(9-39)-bound structure of GLP-1R ECD. Receptor and ligand residues are highlighted in blue for the GLP-1-bound structure and in orange for the exendin-4(9-39)-bound structure. Water molecules in orange are present only in the exendin-4(9-39)-bound structure. A, one diverging residue, Val ${ }^{33 *}$ of GLP-1 and Lys ${ }^{27 * *}$ of exendin-4(9-39), causes a shift in the conformations of four residues, namely Glu ${ }^{127}$, Leu ${ }^{123}, \mathrm{Arg}^{121}$, and Pro ${ }^{119}$. $B$, GLP-1-specific conformations affect the conserved core of the ECD by rotating the guanidine group of $\mathrm{Arg}^{102}$ and by decreasing the distance between $\mathrm{Asp}^{67}$ and $\mathrm{Arg}^{102}$ compared with the exendin-4(9-39)-bound structure without affecting the relative position of $\operatorname{Trp}^{72}$ and $\operatorname{Trp}^{110}$.

ecule, which is also coordinated by the backbone carbonyl groups of $\mathrm{Asp}^{67}$ and Leu ${ }^{32 *}$ (Fig. 2C). A water molecule is coordinated by the same residues in the exendin-4(9-39)-bound ECD, and $\operatorname{Arg}^{121}$ interacts with the backbone carbonyl of Lys $^{27 * *}$ of exendin-4(9-39) in a manner similar to the interaction with $\mathrm{Val}^{33 *}$ of GLP-1. Even though exendin-4 has a C-terminal nine-residue extension, the so-called Trp cage, the extent of the $\alpha$-helix is similar for GLP- 1 and exendin-4, and this particular length of the $\alpha$-helix fits nicely into the ECD binding pocket.

Judging from the two ligand-bound ECD structures, the hydrophobic ligand-receptor interface is highly conserved, and the C-terminal $\alpha$-helical structure of the ligands ends at the same position with a similar arrangement of receptor interactions mediated by the backbone of the ligand. Hence, the differential affinity for the ECD may best be explained by the lower $\alpha$-helical propensity of GLP-1 in solution and by weaker receptor interactions compared with exendin-4, as suggested previously (27).

Unique Structural Features of the GLP-1-bound Extracellular Domain - The divergent residues in GLP-1 and exendin-4 are not only responsible for the different physical properties of the ligands in solution and their differential affinity for the GLP-1R ECD, they also influence the conformation of certain residues in the ECD structures. The crystal structure presented here suggests that one diverging residue in the two ligands $\left(\mathrm{Val}^{33 *}\right.$ of GLP-1 and Lys ${ }^{27 * * *}$ of exendin-4(9-39)) causes a shift in the conformations of four residues in (or close to) the binding pocket of the ECD, namely $\mathrm{Glu}^{127}$, $\mathrm{Leu}^{123}, \mathrm{Arg}^{121}$, and Pro ${ }^{119}$ (Fig. 3A). In exendin-4(9-39), $\mathrm{Lys}^{27 * *}$ interacts with $\mathrm{Glu}^{127}$, and the positioning of the $\operatorname{Lys}^{27 * *}$ side chain appears to be guided by a hydrophobic interaction with Leu ${ }^{123}$. In GLP-1, $\mathrm{Val}^{33 *}$ is unable to interact with $\mathrm{Glu}^{127}$ causing $\mathrm{Glu}^{127}$ to change rotamer conformation and point its side chain away from GLP-1. The side chain of Leu ${ }^{123}$ is flipped toward $\mathrm{Arg}^{121}$, which again is flipped toward Pro ${ }^{119}$, thereby closing an otherwise water-accessible cavity observed in the exendin-4(9-39)-bound structure (Fig. $3 A$ ). The closing of this cavity is assisted by a side chain flip of Pro ${ }^{119}$ toward $\mathrm{Arg}^{121}$. The apparent GLP-1-specific conformations affect the conserved core of the ECD by rotating the guanidine group of $\mathrm{Arg}^{102}$ and by decreasing the distance between $\mathrm{Asp}^{67}$ and $\mathrm{Arg}^{102}$ compared with the exendin-4(939)-bound structure without affecting the relative position and conformation of $\operatorname{Trp}^{72}$ and $\operatorname{Trp}^{110}$ (Fig. $3 B$ ). This enables a direct interaction through a hydrogen bond between $\mathrm{Asp}^{67}$ and $\mathrm{Arg}^{102}$ unlike what we observed in the exendin4(9-39)-bound structure, where a water molecule mediated the interaction between $\mathrm{Asp}^{67}$ and $\mathrm{Arg}^{102}$ (Fig. 3B). The functional consequences of the ligand-specific conformational differences are not known.

Site-directed Mutagenesis of the GLP-1R-To link the structural information of the isolated ECD with the binding and functional properties of the full-length receptor, we targeted the ligand-binding site of the ECD by site-directed mutagenesis. The mutants were characterized by their ability to bind GLP-1 and exendin-4, using the agonist ${ }^{125}$ I-GLP-1 tracer, and by their ability to stimulate cAMP production in response to GLP-1 and exendin-4 (Table 2). The main objective was to search for mutations with differential effect on GLP-1 and exendin-4. We initially focused on $\mathrm{Glu}^{127}$, which showed an obvious conformational difference in the two ligand-bound structures (Fig. $3 A$ ), Glu ${ }^{127}$ interacts directly with exendin4(9-39) but not with GLP-1 (18). The ECD structures suggest that the hydrogen-bonding potential of $\mathrm{Glu}^{127}$ is important for exendin-4 binding but not for binding of GLP-1, and this is supported by the site-directed mutagenesis data (Table 2). Mutation of $\mathrm{Glu}^{127}$ to Ala reduced the affinity for exendin- 4 but not for GLP-1 (6.8- versus 1.7-fold, respectively). Glu ${ }^{128}$ interacts with a positively charged residue in both GLP-1 and exendin-4, which may explain why the E128A substitution did not have a differential effect on the binding affinity of GLP-1 and exendin-4. The differential effect of the E127A mutation on GLP-1 and exendin-4 binding is rather small compared with the differential affinity of the isolated ECD shown previously (27). Clearly, the superior helical propensity of exendin-4 contributes strongly to its high affinity for the ECD.

Several interactions are conserved in the two ECD structures, and mutagenesis of the implicated receptor residues was not expected to have differential effects on ligand binding (Table 2). Surprisingly, the L32A mutation reduced both the affinity and potency of exendin-4 relative to GLP-1 (7.1- and 9.5-fold, respectively, see Table 2 and Fig. 4), demonstrating a ligandspecific effect of the L32A mutation. Neither the potency nor 


\section{TABLE 2}

Functional and binding experiments with GLP-1R mutants

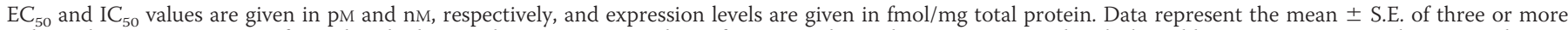

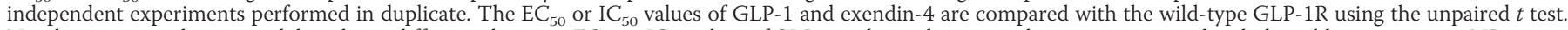

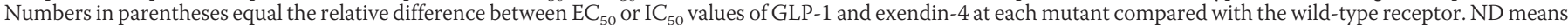
not detectable, possibly due to no expression or no binding. " indicates $p<0.05$; ${ }^{* *}, p<0.01$; and no asterisk means no significant difference.

\begin{tabular}{|c|c|c|c|c|c|}
\hline \multirow{2}{*}{ Mutant } & \multicolumn{2}{|c|}{$\mathrm{EC}_{50}$} & \multicolumn{2}{|c|}{$\mathrm{IC}_{50}$} & \multirow{2}{*}{ Expression level } \\
\hline & GLP-1 & Exendin-4 & GLP-1 & Exendin-4 & \\
\hline & \multicolumn{2}{|c|}{$p_{M}$} & \multicolumn{2}{|c|}{$n_{M}$} & $\mathrm{fmol} / \mathrm{mg}$ \\
\hline Wild type & $11 \pm 3.2$ & $5.5 \pm 1.7$ & $1.0 \pm 0.20$ & $0.76 \pm 0.19$ & $5.5 \pm 0.16$ \\
\hline $\mathrm{L} 32 \mathrm{~A}$ & $12 \pm 2.7(1.1)$ & $52 \pm 24(9.5)$ & $1.1 \pm 0.17(1.1)$ & $5.4 \pm 1.5^{*}(7.1)$ & $6.0 \pm 0.40$ \\
\hline T35A & $30 \pm 7.4(2.7)$ & $23 \pm 12(4.2)$ & $3.1 \pm 0.80(3.1)$ & $0.44 \pm 0.1^{* *}(0.6)$ & $0.38 \pm 0.01$ \\
\hline V36A & $57 \pm 32(5.2)$ & $36 \pm 20(6.5)$ & $2.8 \pm 0.86(2.8)$ & $0.98 \pm 0.34$ & $5.7 \pm 0.28$ \\
\hline E68A & $15 \pm 2.4(1.4)$ & $9.5 \pm 4.2(1.7)$ & $1.9 \pm 0.90(1.9)$ & $0.48 \pm 0.07(0.6)$ & $5.7 \pm 0.07$ \\
\hline Y69A & ND & ND & ND & ND & ND \\
\hline Y88A & ND & ND & ND & ND & ND \\
\hline L89A & ND & ND & ND & ND & ND \\
\hline P90A & $55 \pm 12 *(5.0)$ & $30 \pm 7.3^{*}(5.5)$ & $2.8 \pm 1.6(2.8)$ & $1.6 \pm 0.28(2.1)$ & $5.6 \pm 0.22$ \\
\hline R121A & $51 \pm 13^{*}(4.6)$ & $44 \pm 10^{*}(8.0)$ & $2.3 \pm 1.1(2.3)$ & $1.2 \pm 0.02(1.6)$ & $5.7 \pm 0.37$ \\
\hline L123A & $17 \pm 4.6(1.5)$ & $9.5 \pm 1.9(1.7)$ & $1.1 \pm 0.38$ & $0.33 \pm 0.04(0.4)$ & $2.6 \pm 0.09$ \\
\hline E127A & $13 \pm 4.2(1.2)$ & $11 \pm 0.45^{*}(2.0)$ & $1.7 \pm 0.76(1.7)$ & $5.2 \pm 2.0(6.8)$ & $5.6 \pm 0.46$ \\
\hline E127Q & $12 \pm 3.3(1.1)$ & $6.8 \pm 1.4(1.2)$ & $1.1 \pm 0.27(1.1)$ & $0.82 \pm 0.15$ & $6.11 \pm 0.21$ \\
\hline E128A & $28 \pm 6.2(2.5)$ & $25 \pm 6.7^{*}(4.5)$ & $2.7 \pm 0.91(2.7)$ & $1.8 \pm 0.48(2.4)$ & $6.0 \pm 0.49$ \\
\hline E128Q & $10 \pm 3.0(0.9)$ & $8.0 \pm 3.3(1.5)$ & $0.66 \pm 0.11(0.7)$ & $0.45 \pm 0.1(0.6)$ & $5.2 \pm 0.12$ \\
\hline
\end{tabular}
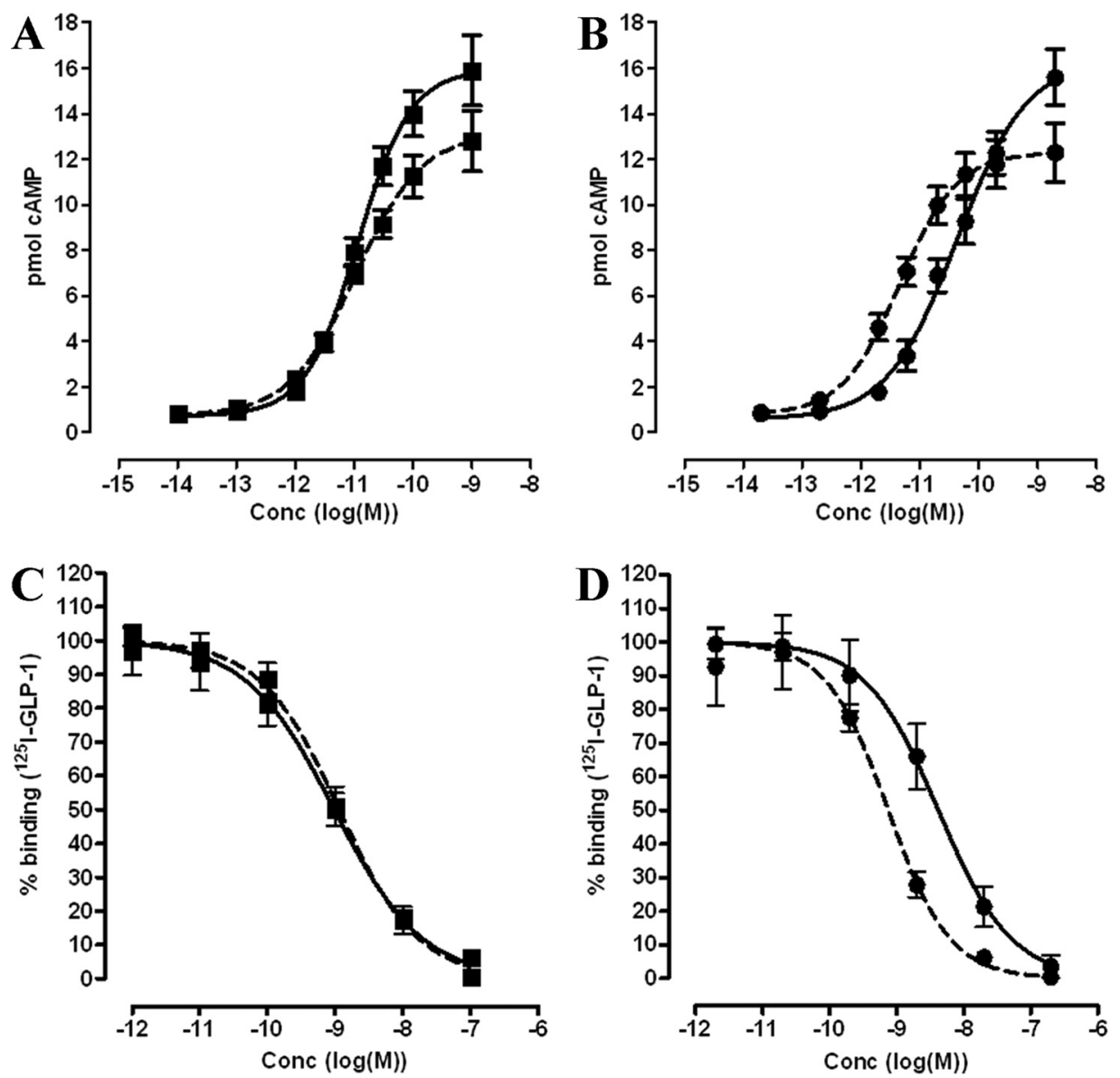

FIGURE 4. Functional and binding properties of the L32A GLP-1R mutant. Upper panel, stimulation of cAMP production by transiently transfected HEK293 cells expressing the L32A mutant by GLP-1 (squares, A) and exendin-4 (circles, B). Dashed dose-response curves represent CAMP production by GLP-1 and exendin-4 at the wild-type GLP-1R, respectively. Lower panel, competition binding assay on plasma membranes from transiently transfected HEK293 cells expressing the L32A mutant. GLP-1 binding curves are presented with squares $(C)$ and exendin-4 curves with circles $(D)$. Dashed binding curves represent ${ }^{125} \mathrm{I}-\mathrm{GLP}-1$ displacement by GLP-1 and exendin-4 at the wild-type GLP-1R. Data are normalized according to ${ }^{125}$ I-GLP-1 binding and correspond to three independent experiments performed in duplicate.

the affinity of GLP-1 was affected by the L32A mutation (Fig. 4), and the expression level of the receptor was similar to wild-type GLP-1R, which confirmed the structural integrity of this receptor mutant. $\mathrm{Leu}^{32}$ is the first residue in the $\alpha$-helix of the GLP-1R ECD, and it defines the border of the hydrophobic binding cavity by interacting with $\mathrm{Ala}^{24 *}, \mathrm{Ala}^{25 *}$, and Phe $^{28 *}$ (Fig. 2B). The results suggest that $\mathrm{Leu}^{32}$ is important for the binding of exendin-4 but not for the binding of GLP-1 to GLP-1R. It is difficult to give a structural explanation of the ligand-specific effect of the L32A mutation by comparing the two ligand-bound forms of the ECD, because the structural differences in this region are quite subtle. Nevertheless, the ligand-specific effect of the L32A mutation supports the existence of differences in the binding modes of GLP-1 and exendin-4 to the full-length GLP-1R. Clearly, the two-domain binding mechanism of the full-length GLP$1 \mathrm{R}$ is more complex than binding of the isolated ECD.

Conformation of GLP-1, Receptor-bound and in Solution-GLP-1 is highly flexible in aqueous buffers, whereas in trifluoroethanol a singlestranded $\alpha$-helix forms ( $\mathrm{Thr}^{13 *}$ to Lys $^{34 *}$ ) with a less defined $\alpha$-helical region around $\mathrm{Gly}^{22 *}$, as demonstrated by NMR spectroscopy (33, 39). Structure-activity studies of GLP-1 showed that side chain to side chain cyclization by lactam bridge formation of residues 16-20 and 18-22 were well tolerated. Cyclization of residues 11-15 improved potency for GLP-1R compared with the linear coun- 

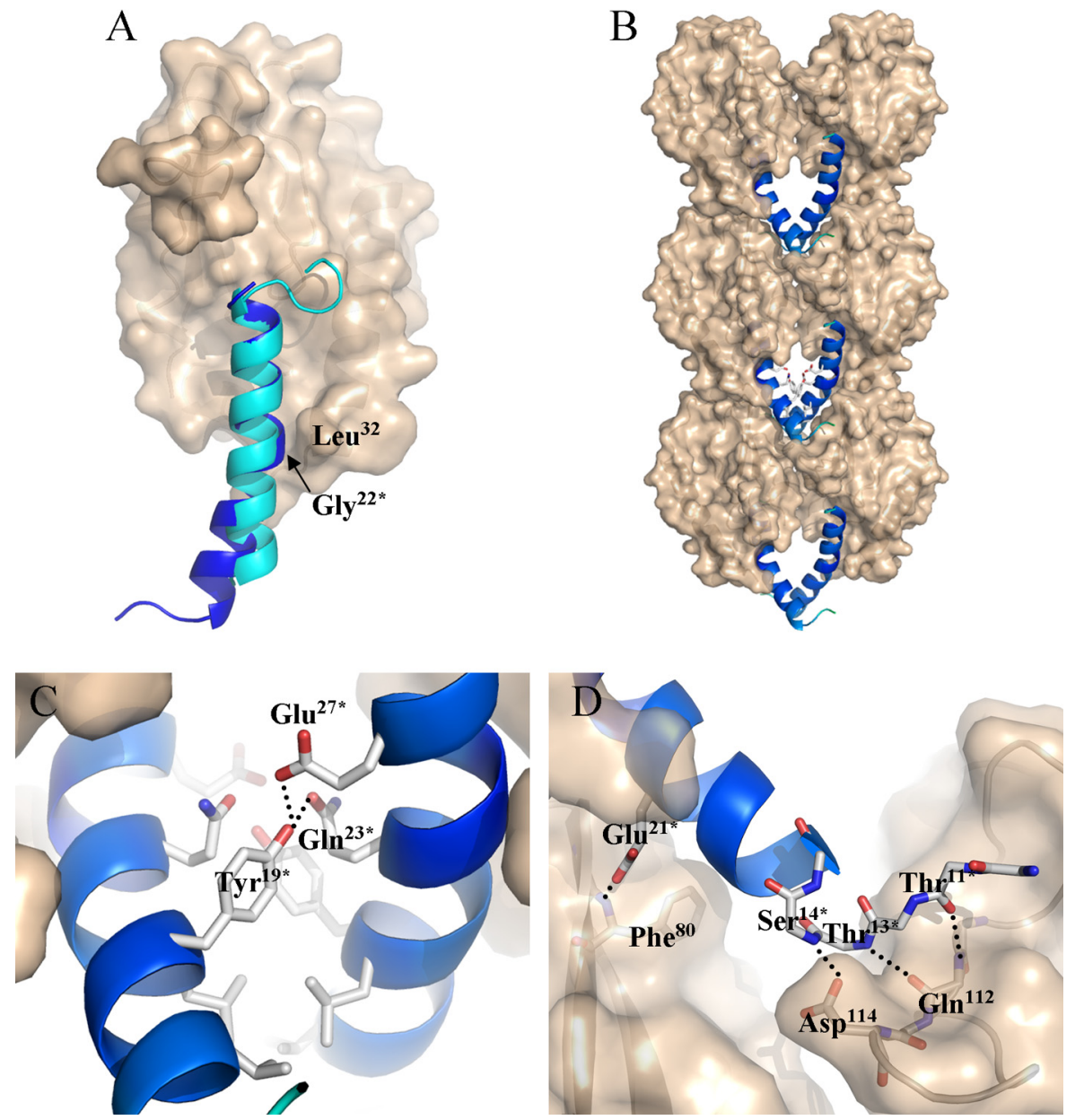

FIGURE 5. Crystal packing. A, superposition of ECD-bound GLP-1 (blue) and exendin-4(9-39) (cyan). GLP-1 residue Gly ${ }^{22 *}$ denotes a kink in the $\alpha$-helix, which is situated in close proximity to Leu ${ }^{32}$ of the ECD. $B$, crystal packing involving symmetry-related complex molecules. C, ribbon diagram of GLP-1 (blue) and its interactions with the ligand of a symmetry-related molecule. Residues $\mathrm{Tyr}^{19 *}, \mathrm{Gl}^{23 *}$, and $\mathrm{Glu}^{27 *}$ are shown as sticks, and the surface of the GLP-1R ECD is shown in gray. The packing of complex molecules allows Tyr ${ }^{19 *}$ to interact with $\mathrm{Gln}^{23 *}(3 \AA)$ and $\mathrm{Glu}^{27 *}(2.5 \AA)$ in a symmetry-related ligand molecule. $D$, interactions between GLP-1 and residues of symmetry-related ECD molecules. GLP-1 residues $\mathrm{Thr}^{11 *} \mathrm{Thr}^{13 *}$, Ser ${ }^{14 *}$, and Glu ${ }^{21 *}$ are shown as sticks. The backbone carbonyl of Thr ${ }^{11 *}$ could form a weak hydrogen bond $(3.2 \AA)$ to the backbone amide of $\mathrm{Gln}^{112}$, the backbone amide of $\operatorname{Thr}^{13 *}$ could form a hydrogen bond ( $\left.2.9 \AA\right)$ to the backbone carbonyl of $\mathrm{Gln}^{112}$, and the backbone amide of $\operatorname{Ser}^{14 *}$ may form a hydrogen bond $(3 \AA)$ to the side chain of $A_{s p}{ }^{114}$. The side chain of $\mathrm{Glu}^{21 *}$ forms a hydrogen bond to the backbone amide of $\mathrm{Phe}^{80}(2.6 \AA)$.

terpart $(40,41)$. These data support the existence of an $\alpha$-helical conformation in the N-terminal part of GLP-1 when bound to the full-length GLP-1R. It is interesting that in the ECD-bound structure, the $\mathrm{Thr}^{13 *}-\mathrm{Glu}^{21 *}$ segment of GLP-1 adopts an $\alpha$-helical conformation even though this segment does not interact with the ECD. The C-terminal segment of GLP-1 $\left(\mathrm{Ala}^{24 *}-\mathrm{Val}^{33 *}\right)$ is stabilized in a specific $\alpha$-helical conformation through binding to the ECD. This may subsequently stabilize an $\alpha$-helical conformation in the $\mathrm{N}$-terminal part of the ligand $\left(\mathrm{Thr}^{13 *}-\mathrm{Glu}^{21 *}\right)$. This hypothesis is supported by the solution structure of GLP-1 in different concentrations of trifluoroethanol (39). GLP-1 is a random coil in pure water, but adding trifluoroethanol enables the C-terminal segment of GLP-1 to adopt an $\alpha$-helix conformation. The $\mathrm{C}$-terminal $\alpha$-helix is gradually extended toward the $\mathrm{N}$-terminus of the peptide with increasing concentrations of trifluoroethanol (39), and it seems possible that a similar mechanism is initiated upon binding of GLP-1 to the ECD. It was recently proposed that $\alpha$-helix for- mation of the ligand upon binding to the ECD is an important step in the activation of class B GPCRs (23).

As shown in Fig. $5 A$, the $\alpha$-helix of GLP-1 has a central distortion of the backbone around $\mathrm{Gly}^{22 *}$, which is not observed in the exendin-4(939)-bound structure. The distortion is also observed in the NMR structures of GLP-1 in solution (39). However, we cannot exclude that the kink observed in the crystal structure is a result of crystal packing between the $\mathrm{N}$-terminal part of GLP-1 ( Gly $\left.^{10 *}-\mathrm{Glu}^{21 *}\right)$ and symmetry-related ECDs rather than a functionally important characteristic of GLP-1 (Fig. 5, B-D). Substitution of $\mathrm{Gly}^{22 *}$ with Ala was previously shown not to affect the functionality or the binding affinity of GLP-1, which suggests that flexibility around $\mathrm{Gly}^{22 *}$ is not required for binding to or activation of GLP-1R (38). Interestingly, $\mathrm{Leu}^{32}$ of the ECD is positioned right next to the kink of GLP-1 (Fig. $5 A$ ). Thus, we have demonstrated a ligand-specific effect of the L32A mutation and have shown that ECD-bound GLP-1 has a kink right next to $\mathrm{Leu}^{32}$, whereas ECD-bound exendin-4(9-39) is straight. This may be a coincidence, but it is tempting to speculate that there is a connection between the structural difference of the ligands (kinked or straight helix) and the differential effect of the L32A mutant on binding of the ligands.

A three-dimensional model of GLP-1R was recently published (21). From the NMR structure of GLP-1 in trifluoroethanol (Protein Data Bank code 1D0R (39)), it was suggested that GLP-1 might assume one of two forms when bound to GLP-1R, a slightly kinked $\alpha$-helix or an L-shaped $\alpha$-helix, and the authors concluded that the L-shaped $\alpha$-helix conformation of GLP-1 seemed more reasonable (21). The crystal structure presented here is more compatible with the kinked conformation of GLP-1.

The structure of $\mathrm{His}^{7 * *}-\mathrm{Gly}^{10 *}$ was not determined in this study probably due to the inherent flexibility in this part of GLP-1 and other peptide ligands for class B receptors (33, 39, $42,43)$. The only structural evidence showing a unique conformation comes from a structural study of PACAP(1-21) comparing micelle- and receptor-bound states. Residues 1-7 of PACAP (1-21) adopt a specific $\beta$-coil structure upon receptor binding followed by an $\alpha$-helical structure of residues $8-21$ (44). The relevance of the receptor-bound PACAP $(1-21)$ structure for GLP-1 in particular is supported by a previous study of 
chimeric PACAP/GLP-1 peptides (45). Substituting five residues from the N-terminus of GLP-1 with those of PACAP (three nonconserved, Fig. $1 B$ ) had no effect on either the affinity or potency for GLP-1R. Thus, on the basis of both sequence homology and structure-activity, GLP-1 would be expected to adopt a similar conformation upon binding to the GLP-1R TM domain.

Conclusion-The crystal structure presented here shows the molecular details of GLP-1 binding to the GLP-1R ECD, an essential step in the two-domain binding mechanism of GLP-1R and class B GPCRs in general. Collectively, results from structural characterization of GLP-1 in solution, structure-activity analyses of GLP-1 analogues, and the crystal structure of GLP-1 bound to the GLP-1R ECD presented here suggest that GLP-1 is a continuous $\alpha$-helix from $\mathrm{Thr}^{13 *}$ to $\mathrm{Val}^{33 *}$ when bound to the full-length GLP-1R. This is important information for the design of peptide therapeutics targeting GLP1R. GLP-1 and exendin- 4 share the same binding site of the GLP-1R ECD, but the ligand-specific effects on the ECD structure and the ligand-specific effects of receptor mutagenesis support the existence of differences in the binding modes of GLP-1 and exendin- 4 to the full-length GLP-1R. The nature of these differences as well as the active conformation of peptide agonists (kinked or not) and a better understanding of the twodomain binding mechanism await structural characterization of the full-length GLP-1R.

Acknowledgments-We thank Lone Bayer and Thomas S. Harkes for skillful laboratory assistance, the staff at the MAX-lab beamline 1911-3 for technical help during data collection, and Henning Thøgersen for discussions.

\section{REFERENCES}

1. Mojsov, S., Heinrich, G., Wilson, I. B., Ravazzola, M., Orci, L., and Habener, J. F. (1986) J. Biol. Chem. 261, 11880-11889

2. Schmidt, W. E., Siegel, E. G., and Creutzfeldt, W. (1985) Diabetologia 28, 704-707

3. Flint, A., Raben, A., Astrup, A., and Holst, J. J. (1998) J. Clin. Invest. 101, $515-520$

4. Orskov, C., Holst, J. J., and Nielsen, O. V. (1988) Endocrinology 123, 2009-2013

5. Wettergren, A., Schjoldager, B., Mortensen, P. E., Petersen, H., Ørskov, C., and Holst, J. J. (1993) Digestion 54, 384-385

6. Xu, G., Stoffers, D. A., Habener, J. F., and Bonner-Weir, S. (1999) Diabetes 48, 2270-2276

7. Turton, M. D., O'Shea, D., Gunn, I., Beak, S. A., Edwards, C. M., Meeran, K., Choi, S. J., Taylor, G. M., Heath, M. M., Lambert, P. D., Wilding, J. P., Smith, D. M., Ghatei, M. A., Herbert, J., and Bloom, S. R. (1996) Nature 379, $69-72$

8. Göke, R., and Conlon, J. M. (1988) J. Endocrinol. 116, 357-362

9. Thorens, B. (1992) Proc. Natl. Acad. Sci. U.S.A. 89, 8641-8645

10. Foord, S. M., Bonner, T. I., Neubig, R. R., Rosser, E. M., Pin, J. P., Davenport, A. P., Spedding, M., and Harmar, A. J. (2005) Pharmacol. Rev. 57, $279-288$

11. Graziano, M. P., Hey, P. J., and Strader, C. D. (1996) Receptors Channels 4, 9-17

12. Runge, S., Wulff, B. S., Madsen, K., Bräuner-Osborne, H., and Knudsen, L. B. (2003) Br. J. Pharmacol. 138, 787-794

13. Hoare, S. R. (2005) Drug Discov. Today 10, 417-427

14. Grace, C. R., Perrin, M. H., DiGruccio, M. R., Miller, C. L., Rivier, J. E., Vale,
W. W., and Riek, R. (2004) Proc. Natl. Acad. Sci. U.S.A. 101, 12836-12841

15. Pioszak, A. A., Parker, N. R., Suino-Powell, K., and Xu, H. E. (2008) J. Biol. Chem. 283, 32900-32912

16. Sun, C., Song, D., Davis-Taber, R. A., Barrett, L. W., Scott, V. E., Richardson, P. L., Pereda-Lopez, A., Uchic, M. E., Solomon, L. R., Lake, M. R., Walter, K. A., Hajduk, P. J., and Olejniczak, E. T. (2007) Proc. Natl. Acad. Sci. U.S.A. 104, 7875-7880

17. Parthier, C., Kleinschmidt, M., Neumann, P., Rudolph, R., Manhart, S., Schlenzig, D., Fanghänel, J., Rahfeld, J. U., Demuth, H. U., and Stubbs, M. T. (2007) Proc. Natl. Acad. Sci. U.S.A. 104, 13942-13947

18. Runge, S., Thøgersen, H., Madsen, K., Lau, J., and Rudolph, R. (2008) J. Biol. Chem. 283, $11340-11347$

19. Pioszak, A. A., and Xu, H. E. (2008) Proc. Natl. Acad. Sci. U.S.A. 105, 5034-5039

20. Al-Sabah, S., and Donnelly, D. (2003) Br. J. Pharmacol. 140, 339-346

21. Lin, F., and Wang, R. X. (2009) J. Mol. Model 15, 53-65

22. Miller, L. J., Dong, M., Harikumar, K. G., and Gao, F. (2007) Biochem. Soc. Trans. 35, 709-712

23. Parthier, C., Reedtz-Runge, S., Rudolph, R., and Stubbs, M. T. (2009) Trends Biochem. Sci. 34, 303-310

24. Eng, J., Kleinman, W. A., Singh, L., Singh, G., and Raufman, J. P. (1992) J. Biol. Chem. 267, 7402-7405

25. Thorens, B., Porret, A., Bühler, L., Deng, S. P., Morel, P., and Widmann, C. (1993) Diabetes 42, $1678-1682$

26. López de Maturana, R., Willshaw, A., Kuntzsch, A., Rudolph, R., and Donnelly, D. (2003) J. Biol. Chem. 278, 10195-10200

27. Runge, S., Schimmer, S., Oschmann, J., Schiødt, C. B., Knudsen, S. M., Jeppesen, C. B., Madsen, K., Lau, J., Thøgersen, H., and Rudolph, R. (2007) Biochemistry 46, 5830-5840

28. Al-Sabah, S., and Donnelly, D. (2003) FEBS Lett. 553, 342-346

29. López de Maturana, R., and Donnelly, D. (2002) FEBS Lett. 530, 244-248

30. López de Maturana, R., Treece-Birch, J., Abidi, F., Findlay, J. B., and Donnelly, D. (2004) Protein Pept. Lett. 11, 15-22

31. Montrose-Rafizadeh, C., Yang, H., Rodgers, B. D., Beday, A., Pritchette, L. A., and Eng, J. (1997) J. Biol. Chem. 272, 21201-21206

32. Göke, R., Fehmann, H. C., Linn, T., Schmidt, H., Krause, M., Eng, J., and Göke, B. (1993) J. Biol. Chem. 268, 19650-19655

33. Neidigh, J. W., Fesinmeyer, R. M., Prickett, K. S., and Andersen, N. H. (2001) Biochemistry 40, 13188-13200

34. Neidigh, J. W., Fesinmeyer, R. M., and Andersen, N. H. (2002) Nat. Struct. Biol. 9, 425-430

35. Kabsch, W. (1993) J. Appl. Crystallogr. 26, 795-800

36. Emsley, P., and Cowtan, K. (2004) Acta Crystallogr. D. Biol. Crystallogr. 60, 2126-2132

37. Murshudov, G. N., Vagin, A. A., and Dodson, E. J. (1997) Acta Crystallogr. D Biol. Crystallogr. 53, 240-255

38. Adelhorst, K., Hedegaard, B. B., Knudsen, L. B., and Kirk, O. (1994) J. Biol. Chem. 269, 6275-6278

39. Chang, X. Q., Keller, D., Bjorn, S., and Led, J. J. (2001) Magn. Reson. Chem. 39, 477-483

40. Miranda, L. P., Winters, K. A., Gegg, C. V., Patel, A., Aral, J., Long, J., Zhang, J., Diamond, S., Guido, M., Stanislaus, S., Ma, M., Li, H., Rose, M. J., Poppe, L., and Véniant, M. M. (2008) J. Med. Chem. 51, $2758-2765$

41. Murage, E. N., Schroeder, J. C., Beinborn, M., and Ahn, J. M. (2008) Bioorg. Med. Chem. 16, 10106-10112

42. Braun, W., Wider, G., Lee, K. H., and Wüthrich, K. (1983) J. Mol. Biol. 169, 921-948

43. Thornton, K., and Gorenstein, D. G. (1994) Biochemistry 33, 3532-3539

44. Inooka, H., Ohtaki, T., Kitahara, O., Ikegami, T., Endo, S., Kitada, C., Ogi, K., Onda, H., Fujino, M., and Shirakawa, M. (2001) Nat. Struct. Biol. 8, 161-165

45. Xiao, Q., Giguere, J., Parisien, M., Jeng, W., St-Pierre, S. A., Brubaker, P. L., and Wheeler, M. B. (2001) Biochemistry 40, 2860-2869

46. DeLano, W. L. (2002) The PyMOL Molecular Graphics System, DeLano Scientific LLC, San Carlos, CA 


\section{Supplemental Data}

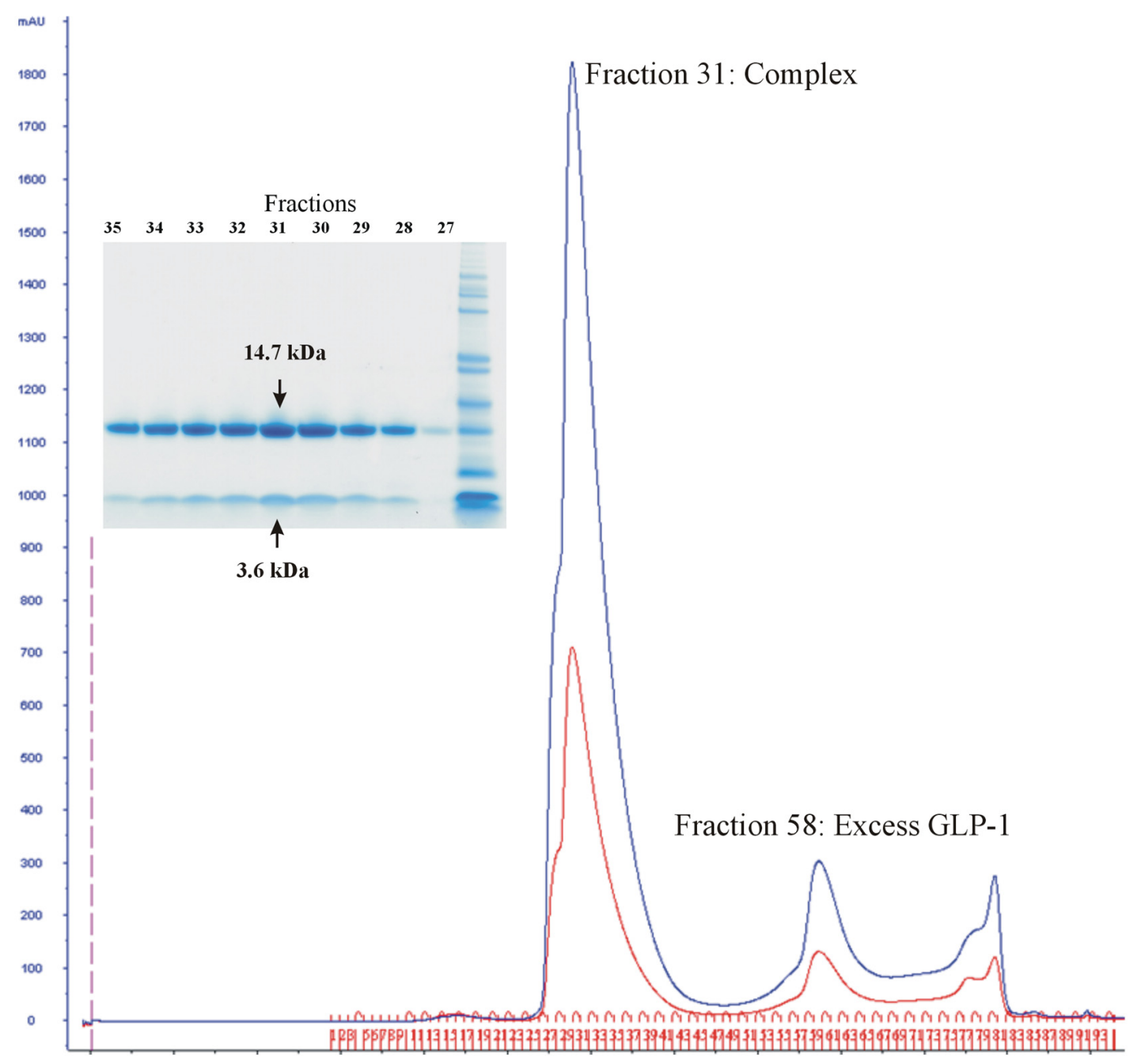

Figure S1. SDS-PAGE of the purified GLP-1-bound ECD

The GLP-1-bound ECD was purified by size exclusion chromatography and the eluted complex was characterised by SDS-PAGE. Fractions 27-35 from Superdex75 are indicated. The overall molecular mass (MW) of the purified complex is $18.3 \mathrm{kDa}$, where MW of the GLP-1 ECD is $14.7 \mathrm{kDa}$ and MW of GLP-1(7-37) is $3.6 \mathrm{kDa}$. 


\section{AFFINITY SITES}

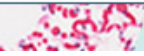

Protein Structure and Folding:

Crystal Structure of Glucagon-like

Peptide-1 in Complex with the

Extracellular Domain of the Glucagon-like

Peptide-1 Receptor

Christina Rye Underwood, Patrick Garibay,

Lotte Bjerre Knudsen, Sven Hastrup, Günther

H. Peters, Rainer Rudolph and Steffen

Reedtz-Runge

J. Biol. Chem. 2010, 285:723-730.

doi: 10.1074/jbc.M109.033829 originally published online October 27, 2009

Access the most updated version of this article at doi: 10.1074/jbc.M109.033829

Find articles, minireviews, Reflections and Classics on similar topics on the JBC Affinity Sites.

Alerts:

- When this article is cited

- When a correction for this article is posted

Click here to choose from all of JBC's e-mail alerts

Supplemental material:

http://www.jbc.org/content/suppl/2009/10/27/M109.033829.DC1.html

This article cites 45 references, 17 of which can be accessed free at http://www.jbc.org/content/285/1/723.full.html\#ref-list-1 